\title{
Co-infections with multiple genotypes of Anaplasma marginale in cattle indicate pathogen diversity
}

\author{
Paidashe Hove ${ }^{1,2}$, Mamohale E. Chaisi ${ }^{1,3}$, Kelly A. Brayton ${ }^{1,4}$, Hamilton Ganesan ${ }^{5}$, Helen N. Catanese ${ }^{6}$, \\ Moses S. Mtshali ${ }^{3,7}$, Awelani M. Mutshembele ${ }^{3,8}$, Marinda C. Oosthuizen ${ }^{1}$ and Nicola E. Collins ${ }^{1 *}$
}

\begin{abstract}
Background: Only a few studies have examined the presence of Anaplasma marginale and Anaplasma centrale in South Africa, and no studies have comprehensively examined these species across the whole country. To undertake this country-wide study we adapted a duplex quantitative real-time PCR ( $q P C R$ ) assay for use in South Africa but found that one of the genes on which the assay was based was variable. Therefore, we sequenced a variety of field samples and tested the assay on the variants detected. We used the assay to screen 517 cattle samples sourced from all nine provinces of South Africa, and subsequently examined A. marginale positive samples for msp1a genotype to gauge strain diversity.

Results: Although the A. marginale msp1 $\beta$ gene is variable, the qPCR functions at an acceptable efficiency. The $A$. centrale groEL gene was not variable within the GPCR assay region. Of the cattle samples screened using the assay, $57 \%$ and $17 \%$ were found to be positive for A. marginale and A. centrale, respectively. Approximately $15 \%$ of the cattle were co-infected. Mspla genotyping revealed 36 novel repeat sequences. Together with data from previous studies, we analysed the Msp1a repeats from South Africa where a total of 99 repeats have been described that can be attributed to 190 mspla genotypes. While 22\% of these repeats are also found in other countries, only two South African genotypes are also found in other countries; otherwise, the genotypes are unique to South Africa.

Conclusions: Anaplasma marginale was prevalent in the Western Cape, KwaZulu-Natal and Mpumalanga and absent in the Northern Cape. Anaplasma centrale was prevalent in the Western Cape and KwaZulu-Natal and absent in the Northern Cape and Eastern Cape. None of the cattle in the study were known to be vaccinated with $A$. centrale, so finding positive cattle indicates that this organism appears to be naturally circulating in cattle. A diverse population of A. marginale strains are found in South Africa, with some mspla genotypes widely distributed across the country, and others appearing only once in one province. This diversity should be taken into account in future vaccine development studies.
\end{abstract}

Keywords: msp1a, msp1 $\beta$, groEL, qPCR, Next-generation amplicon sequencing

\section{Background}

Bovine anaplasmosis is one of the most economically important tick-borne diseases of ruminants the world over [1-3]. The causative agent of the disease is the rickettsia Anaplasma marginale, a gram-negative, obligate intra-erythrocytic pathogen of the order Rickettsiales

\footnotetext{
*Correspondence: nicola.collins@up.ac.za

${ }^{1}$ Vectors and Vector-borne Diseases Research Programme, Department of Veterinary Tropical Diseases, Faculty of Veterinary Science, University of Pretoria, Pretoria, South Africa

Full list of author information is available at the end of the article
}

and family Anaplasmataceae [2, 4-6]. Anaplasma marginale is the most prevalent vector-borne pathogen and is found on all six inhabited continents [5, 7-9]. Approximately 20 tick species worldwide have been implicated as biological vectors of the pathogen, although mechanical and transplacental transmission has also been reported [2, 3, 10-15]. Anaplasma centrale, considered by some authors to be a subspecies of $A$. marginale, generally causes a milder, less virulent form of the disease, with occasional clinical cases [16]. Infection with 
A. centrale confers immunity to A. marginale. Anaplasma centrale has therefore been employed as a live vaccine $[2,17]$. In South Africa, bovine anaplasmosis is found in most of the cattle farming regions and is an economically important tick-borne disease [2, 3, 17]. It is endemic in eight of the nine provinces of the country [3], except the Northern Cape where the tick vectors are absent. Five tick species, namely Rhipicephalus decoloratus, $R$. microplus, $R$. evertsi evertsi, $R$. simus and Hyalomma marginatum rufipes, have been shown experimentally to be capable of transmitting A. marginale in South Africa [12].

Recently we compared three nucleic acid-based tests for detecting A. marginale and A. centrale [18]. The nested polymerase chain reaction (nPCR) assay (which targets the msp $1 \beta$ gene of $A$. marginale and msp 2 of $A$. centrale $[19,20])$ detected fewer $A$. marginale positive samples than the duplex quantitative real-time PCR (qPCR) (which detects $m s p 1 \beta$ of $A$. marginale and groEL of $A$. centrale [20, 21]). This discrepancy was found to be due to sequence variation in the $m s p 1 \beta$ gene in the target region of one of the internal PCR primers. The reverse line blot (RLB) hybridization assay [22], in which species-specific sequences in the 16S rRNA gene of Anaplasma and Ehrlichia species are detected, was found to be less sensitive than the qPCR and nPCR assays. The qPCR assay was thus shown to be the most appropriate assay for detection of $A$. marginale in blood samples from cattle [18]. However, the identification of $m s p 1 \beta$ gene sequence variants indicates the need to assess sequence variation in the target regions of the $\mathrm{qPCR}$ assays, to ensure that all $A$. marginale and $A$. centrale genetic variants are detected.

A genotyping method based on the msp1 $\alpha$ gene [23-26], which encodes major surface protein 1a (Mspla) [27, 28], has been developed for characterizing $A$. marginale strains in positive samples and has been applied throughout the world. Anaplasma marginale msp1 $\alpha$ genotyping is not only useful for understanding the genetic diversity of the pathogen but has also been used to elucidate host-pathogen interactions and co-evolution [8, 25, 29-32]. Msp1 $\alpha$ genotyping relies on variation in tandem repeats at the $5^{\prime}$ end of the gene that varies both in number and sequence. Mspla repeats are identified in the deduced amino acid sequence and are given alphanumeric names to distinguish between sequence variants; the Mspla repeat structure determines the $m s p 1 \alpha$ genotype of a strain. Over 250 Mspla repeats have been described, making it a useful marker for discriminating $A$. marginale strains [24-26, 28, 31, 33, 34]. In the South African context, $m s p 1 \alpha$-based genotyping has revealed diversity in A. marginale strains across the country, and novel repeats have been identified, although other repeats are identical to those detected in Europe and the USA [24, 25]. Although infection exclusion was thought to result in only one A. marginale genotype in individual cattle and ticks [35], more recently, infections with multiple distinct $m s p 1 \alpha$ and $m s p 2$ genotypes have been identified in herds in endemic areas with high infection rates [36-40].

In this study, we used next-generation amplicon sequencing to assess the level of variation in the qPCR target regions of the msp1 $\beta$ (A. marginale) and groEL (A. centrale) genes from field samples in order to ensure that the duplex qPCR assay $[20,21]$ was able to detect all $A$. centrale and $A$. marginale genetic variants in South Africa. The assay was then used to screen cattle samples from all nine provinces of the country for the presence of these organisms, followed by $m s p 1 \alpha$ genotyping from selected positive samples. We cloned msp1 $\alpha$ PCR amplicons and sequenced multiple clones to maximize the diversity of $A$. marginale genotypes detected from individual animals.

\section{Methods}

Blood sample collection and genomic DNA extraction

A total of 517 EDTA blood samples were obtained from mixed breeds of cattle from all nine provinces of South Africa (Table 1). These consisted of fresh blood samples collected from cattle in the Mnisi communal area (79) and a private farm near Lydenburg (17), Mpumalanga Province, and 148 samples collected from cattle at the University of Pretoria Experimental Farm (Proefplaas, Gauteng Province), as well as 284 frozen cattle blood samples, collected from different parts of South Africa, obtained from the National Zoological Gardens (NZG), Pretoria, South Africa. Blood samples from cattle were collected according to the animal ethics code of the University of Pretoria in $9 \mathrm{ml}$ Vacuette $^{\circ}$ EDTA tubes (Greiner Bio-One, Kremsmünster, Austria), from the coccygeal vein of cattle that were at least 1 year old. Anaplasma centrale blood vaccine was obtained from Onderstepoort Biological Products (Pretoria, South Africa). Genomic DNA was extracted using the QIAamp DNA Blood Mini Kit (Qiagen, Hilden, Germany) according to the manufacturer's instructions, and DNA was eluted in $100 \mu \mathrm{l}$ elution buffer and stored at $-20^{\circ} \mathrm{C}$.

Table 1 Number and origin of cattle field samples used in the study

\begin{tabular}{ll}
\hline Province & No. of samples \\
\hline Limpopo & 30 \\
Mpumalanga & 115 \\
Gauteng & 183 \\
North West & 30 \\
Free State & 30 \\
KwaZulu-Natal & 30 \\
Northern Cape & 30 \\
Eastern Cape & 43 \\
Western Cape & 26 \\
Total & 517 \\
\hline
\end{tabular}




\section{Next-generation amplicon sequencing of $m s p 1 \beta$ and groEL genes}

Next-generation sequencing (NGS) was used to determine the extent of variation in amplicons of a part of the $m s p 1 \beta$ and groEL genes of $A$. marginale and $A$. centrale in, respectively, 40 and 25 known positive field samples from across South Africa. Twenty $A$. marginale msp $1 \beta$ gene sequences from GenBank (accession numbers: M59845, AF110808-AF110810, AF112479, AF112480, AF111195, AF111197, AF221692, AF348137, AF348138, AY841153, KU647713-KU647720) were aligned using CLC Genomics Workbench 7.5.1 (https://www.qiagenbioinformatics.com) and used to design primers Msp1 $\beta$ F (5'-GAT GAA GCA CCT GAC ACT GGT GAG-3') and Msp1ß_R (5' CGC GTC GAT TGC TGT GC-3') in areas conserved in all of these sequences. The primers amplify a $419 \mathrm{bp}$ fragment of the msp1 $\beta$ gene spanning the qPCR primer and probe area. The primer pair groEL-ACF and groEL-ACR [20] was used to amplify a 522 bp fragment of the groEL gene from both $A$. marginale and $A$. centrale. The primers were modified by adding Illumina-specific adaptor sequences to allow for barcoding of each amplicon and were synthesized at Inqaba Biotechnical Industries (Pretoria, South Africa). The PCRs were performed in a total volume of $25 \mu$ l containing $1 \times$ Phusion Flash High-Fidelity PCR Master Mix (Thermo Fisher Scientific, Waltham, USA), $1.5 \mu \mathrm{M}$ of each primer and $2.5 \mu \mathrm{l}$ genomic DNA (approximately $200 \mathrm{ng}$ ). For amplification of the $m s p 1 \beta$ amplicon, the PCR thermal cycling conditions were $98{ }^{\circ} \mathrm{C}$ for $10 \mathrm{~s}, 40$ cycles of $98^{\circ} \mathrm{C}$ for $5 \mathrm{~s}, 67^{\circ} \mathrm{C}$ for $15 \mathrm{~s}, 72^{\circ} \mathrm{C}$ for $15 \mathrm{~s}$, and a final extension at $72{ }^{\circ} \mathrm{C}$ for $1 \mathrm{~min}$. The same cycling conditions were used for amplification of the groEL amplicon, except that the annealing temperature was $66{ }^{\circ} \mathrm{C}$. The amplicons were purified using the QIAquick gel extraction kit (Qiagen) according to the manufacturer's instructions.

Plasmid controls were included in determining the Taq and sequencing error rate, to distinguish sequence artefacts from real sequence variants [38]. Multiple strains of $A$. marginale are known to be present in South African samples [24, 25], but the relative incidence of different strains in each sample is unknown, and some strains may be present at very low levels. Amplicons were therefore generated from plasmid controls F48a $(A$. marginale msp1 $\beta), 9410 \mathrm{c}(A$. centrale groEL) and $\mathrm{C} 14 \mathrm{c}$ (A. marginale groEL) to determine the frequency of sequence artefacts (including Taq or sequencing errors) expected in the field samples. The positive control plasmids were generated previously from field samples that were positive for $A$. marginale (F48 and $\mathrm{C} 14$ ) and $A$. centrale (9410) [18].

Resulting amplicons were gel purified, end repaired and Illumina-specific adapter sequences were ligated to each amplicon. Following quantification, the samples were individually indexed, and another purification step was performed. Indexed, adapter-ligated amplicons were then sequenced on Illumina's MiSeq platform, using a MiSeq v3 (600 cycles) kit (San Diego, California, USA). About $20 \mathrm{MB}$ of data $(2 \times 300 \mathrm{bp}$ long paired-end reads $)$ were produced for each sample.

Quality filtering was performed on the MiSeq platform, using standard procedures. Only reads that mapped to $A$. centrale groEL 9410c, A. marginale groEL C14c and $A$. marginale msp1 $\beta$ F48a reference sequences [18] were incorporated into the subsequent analysis. The sequences were analysed by first merging corresponding Illumina R1 and $\mathrm{R} 2$ reads, and only merged sequences were analysed further. Again, the groEL and $m s p 1 \beta$ amplicon sequences were mapped to their respective $A$. marginale or $A$. centrale reference sequences. For each set of merged reads, a clustering based on sequence identity was performed. For the groEL control plasmid clone 9410c included to determine the frequency of artefacts, the highest proportion of sequences $(47.6 \%)$ was identical to the $9410 \mathrm{c}$ reference sequence. All other sequences (artefacts) were present at an abundance of less than $1.5 \%$ each, but collectively made up $52.4 \%$ of the sequences. For the msp $1 \beta$ plasmid clone F48c, $63.8 \%$ of the sequences were identical to the F48c reference sequence, and all other sequences were present at an abundance of less than $1.4 \%$, collectively making up $36.2 \%$ of the sequences. Therefore, for the field samples, sequences present at less than $1.5 \%$ of the total after cluster analysis were disregarded as Taq or sequencing errors. In each cluster, sequences that were present at $\geq 1.5 \%$ of the total number of sequences were therefore considered to be true variants and were aligned with published sequences using CLC Genomics Workbench 7.5.1.

\section{Confirmation of $m s p 1 \beta$ variants by Sanger sequencing}

The $m s p 1 \beta$ variants identified by NGS were confirmed by Sanger sequencing in eleven samples. Primers AM456 and AM1164 [19] were used to amplify a 750 bp region of the msp $1 \beta$ gene flanking the qPCR target area. The reaction mixture contained $1 \times$ Phusion Flash High-Fidelity PCR Master Mix (Thermo Fisher Scientific), $0.5 \mu \mathrm{M}$ of each primer, $2.5 \mu \mathrm{l}$ of template DNA (approximately $200 \mathrm{ng}$ ) and molecular grade water to a final volume of $25 \mu \mathrm{l}$. The PCR thermal cycling conditions were $95{ }^{\circ} \mathrm{C}$ for $3 \mathrm{~min}$, 40 cycles of $94{ }^{\circ} \mathrm{C}$ for $10 \mathrm{~s}, 60{ }^{\circ} \mathrm{C}$ for $30 \mathrm{~s}, 72{ }^{\circ} \mathrm{C}$ for $30 \mathrm{~s}$, and a final extension at $72{ }^{\circ} \mathrm{C}$ for $7 \mathrm{~min}$. The PCR products were purified, quantified and cloned using the CloneJET PCR Cloning Kit (Thermo Fisher Scientific). Recombinant plasmids were screened by colony PCR using vectorspecific primers pJET1.2F and pJET1.2R. Plasmid DNA was extracted from recombinants using the High Pure Plasmid Isolation kit (Roche Diagnostics, Basel, Switzerland). Plasmids containing the correct insert were sequenced bidirectionally on an ABI Prism 3100 Genetic Analyzer (Applied 
Biosystems, Foster City, California, USA) at Inqaba Biotechnical Industries. Sequences were assembled and aligned using CLC Genomics Workbench 7.5.1.

\section{Quantitative real-time PCR (qPCR) for specific detection of} A. marginale and $A$. centrale

A duplex qPCR assay with minor modifications for the LightCycler real-time machine (Roche Diagnostics) targeting the msp $1 \beta$ gene of $A$. marginale and the groEL gene of $A$. centrale, was used to detect Anaplasma spp. in genomic DNA samples as previously described [18]. DNA extracted from the $A$. centrale vaccine strain (Onderstepoort Biological Products, Pretoria, South Africa) or field sample 9410 (confirmed to be infected with $A$. centrale by amplification and sequence analysis of the groEL, msp2 and 16S rRNA genes [18]) were used as positive controls. Field samples C14 or C57 (obtained from cattle in the Mnisi Community area) were used as positive controls for A. marginale, and molecular grade water as a negative control. To determine A. centrale loads, DNA was extracted from 10fold serial dilutions of vaccine prepared in uninfected bovine blood. The data were analysed using LightCycler Software version 4.0. (Roche Diagnostics). The linear range of detection and assay efficiency of selected variants were determined as previously described [18].

Amplification, cloning and sequencing of the msp1a gene The repeat-containing region of the $m s p 1 \alpha$ gene was amplified using primers 1733F (5'-TGT GCT TAT GGC AGA CAT TTC C-3') and 2957R (5'-AAA CCT TGT AGC CCC AAC TTA TCC-3') [41]. Phusion Flash High-Fidelity PCR Master Mix (Thermo Fisher Scientific) reactions were set up as for $m s p 1 \beta$. Cycling conditions were $98{ }^{\circ} \mathrm{C}$ for $10 \mathrm{~s}, 30$ cycles of $98{ }^{\circ} \mathrm{C}$ for $1 \mathrm{~s}, 69.1{ }^{\circ} \mathrm{C}$ for $5 \mathrm{~s}$ and $72{ }^{\circ} \mathrm{C}$ for $18 \mathrm{~s}$, and a final extension at $72{ }^{\circ} \mathrm{C}$ for $1 \mathrm{~min}$. If these PCR conditions failed to generate an amplicon for a sample, the PCR was repeated using the Phusion Flash High-Fidelity PCR Master Mix (Thermo Fisher Scientific), and the cycling conditions reported by [41] except that a pre-PCR denaturation at $94{ }^{\circ} \mathrm{C}$ for $3 \mathrm{~min}$ and $\mathrm{Taq}$ activation at $98{ }^{\circ} \mathrm{C}$ for $10 \mathrm{~s}$ were included. Samples were analysed on a $1.5 \%$ agarose gel and those displaying a single, strong band were purified using the Qiagen PCR product purification kit (Qiagen) according to the manufacturers' instructions. Samples containing multiple PCR products and PCR products that produced mixed sequences were cloned into pJET 1.2 (Thermo Fisher Scientific). Recombinant clones and amplicons were sequenced at Inqaba Biotechnical Industries as described above.
Analysis of Msp1a repeats to determine strain type Sequences were assembled and aligned using CLC Genomics Workbench 7.5.1. RepeatAnalyzer [42] was used to identify, curate, map and analyse Mspla repeats and $A$. marginale strains. New names (UP1 to UP36) were given to novel repeats that were not recognized by RepeatAnalyzer. All South African Mspla repeats and msp1 $\alpha$ genotypes $([24,25]$ and this study) were pooled and analysed using RepeatAnalyzer, generating diversity metric scores [42]. For comparison, similar analyses on previously published data from Argentina, Brazil, Mexico, the Philippines and USA, were also carried out.

\section{Results}

Next-generation sequencing of the groEL and $m s p 1 \beta$ genes

A total of 39 A. centrale and 40 A. marginale partial groEL sequences (approximately $520 \mathrm{bp}$ in length) were obtained from 25 bovine samples. The $A$. centrale groEL sequences were conserved within the qPCR target region. The $A$. marginale groEL sequences were also conserved and differed from the $A$. centrale groEL sequences at six nucleotide positions in the probe area and three nucleotide positions in the reverse primer region (Fig. 1a). The A. centrale groEL sequences were identical to published sequences including those with accession numbers AF414867 (Vaccine strain, South Africa), AF414866 (L strain, South Africa) and ACIS_00394 in the complete genome sequence, CP001759 (Israel strain); while the $A$. marginale groEL sequences were similar to the St. Maries (USA) sequence (AM944 in CP000030). For $m s p 1 \beta, 151$ different sequences (partial gene sequence; approximately $420 \mathrm{bp}$ in length) were obtained from a total of 183 sequences from 40 samples. Individual samples contained between one and 11 different msp1 $\beta$ sequences. Eleven variants (designated as SA1SA11) were identified in the qPCR target area (Fig. 1b). Single nucleotide polymorphisms (SNPs) were identified at six positions in the primer and probe regions; individual variants contained one to three of these SNPs. Variants SA1, SA2, SA3, SA4, SA5, SA8 and SA9, were identified in multiple samples, while variants SA6, SA7, SA10 and SA11 occurred in only one sample each. The most common variants were SA2 and SA9, identified from 25 samples each. Both of these variants were widespread in South Africa; SA9 occurred in seven provinces, while SA2 was identified in eight provinces. The greatest number of variants (eight) was identified in samples from the Western Cape.

Variants SA1, SA2, SA4, SA5 and SA7 were cloned and their sequences confirmed by Sanger sequencing. Plasmid DNA from clones of these five variants could be detected by the qPCR assay (Fig. 2a). qPCR assay efficiency for detection of variant SA1 was evaluated in a previous study [18]. Evaluation of the efficiency of the qPCR assay in detecting the two variants (SA2 and SA4) 


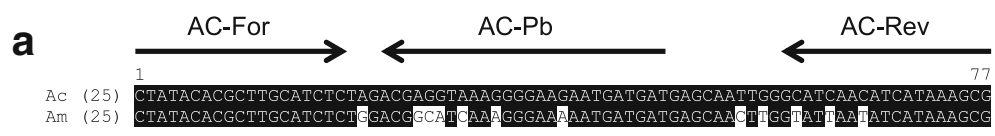

b

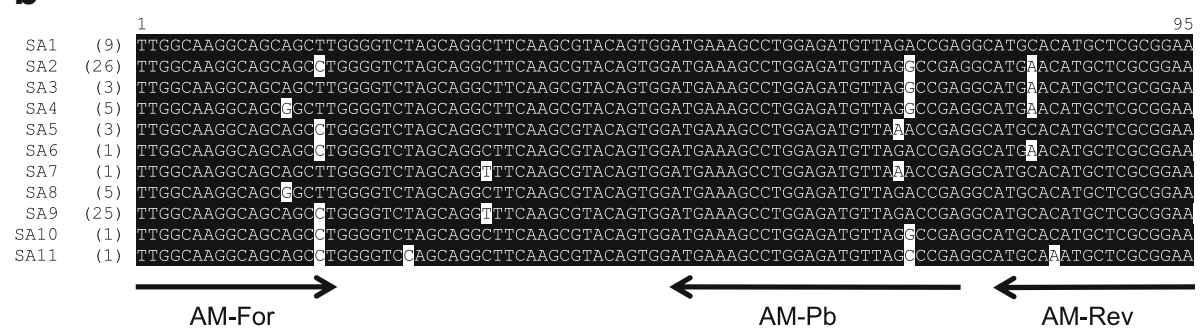

Fig. 1 Sequence alignment of groEL and msp $1 \beta$ sequences in the qPCR target regions. a $A$. centrale (Ac) and A. marginale (Am) groEL gene sequences obtained in this study. $\mathbf{b}$ msp $1 \beta$ gene sequence variants in the qPCR target region (SA1-SA11) obtained in this study. The number in parentheses after each sequence name indicates the number of samples from which each sequence was obtained. The primer and probe regions are indicated by arrows. Identical nucleotides are shown by white text on a black background while sequence variations are represented by black text on a white background

containing the most differences (3 SNPs) in the primer and probe regions indicated that the SNPs did not have any effect on the efficiency of the assay (Fig. 2b).

\section{Detection of low $A$. centrale loads in duplex qPCR}

Serial dilutions of a known amount of $A$. centrale blood vaccine was used in the duplex qPCR to establish our ability to detect low parasite loads in blood samples (Fig. 2c). We could detect as few as ten infected red blood cells (10 iRBCs) per $20 \mu \mathrm{l}$ reaction. When working directly from genomic DNA extracted from a blood sample, the efficiency of the qPCR becomes $119 \%$. This apparent increase in efficiency compared to the assay applied to plasmids ( $E=103 \%$, Fig. $2 b$ ) is likely due to inhibitors coextracted with the genomic DNA.

\section{Detection of $A$. marginale and $A$. centrale infections in field samples by the duplex qPCR assay}

FAM fluorescence (530 nm) was generated in A. marginale-positive samples and LC-610 $(610 \mathrm{~nm})$ signals were generated in $A$. centrale-positive samples. No amplification was detected from the negative control. The qPCR assay detected $A$. marginale and $A$. centrale in $56.8 \%$ and $17.2 \%$ of the samples $(n=517)$, respectively. Eighty-one (15.3\%) samples had mixed infections. Anaplasma marginale-positive cattle were identified in all provinces except Northern Cape (Fig. 3). Most of the A. marginalepositive samples were identified in KwaZulu-Natal (100\%), Western Cape (88.5\%) and Mpumalanga (77.4\%), while most of the $A$. centrale-positive cattle were from KwaZulu-Natal (76.7\%) and Western Cape (69.2\%). Anaplasma centrale was not identified in samples from the Eastern Cape and Northern Cape.
Msp1a genotyping and sequence analysis of $A$. marginale Msp1a repeats identified in this study

To examine the $A$. marginale strain diversity in the sample set, $m s p 1 \alpha$ genotypes were determined in samples that were shown to be $A$. marginale-positive using the duplex qPCR. In our study, a total of 143 genotypes were found from 627 msp1 $\alpha$ sequences, which were generated from 85 samples from across South Africa. An average of 10.5 samples was analysed per province, and an average of 27.8 genotypes was identified per province. Thirty-six Msp1a repeats that have not previously been reported were found, and these were designated UP1-UP36 (Fig. 4). The novel repeats were 28-29 amino acids in length, except UP12 which was found to have an arginine $(\mathrm{R})$ insertion at position 12, making it the longest repeat at 30 amino acids. Alignment of 234 published repeats shows that Serine $(\mathrm{S})$ residues tend to be highly conserved (data not shown). Interestingly, $\mathrm{S}$ residues in the repeat region are thought to be $\mathrm{O}$ glycosylated and to facilitate the adhesion function of the Msp1a protein [43]. The 36 novel repeats (Fig. 4) all contained variations in the previously reported immunodominant and linear B-cell epitope SSAGGQQQESS (positions 4-14), the neutralisation-sensitive B-cell epitope Q/EASTSS (positions 21-26) and the T-cell epitope VSSQSDQASTSSQLG (positions 15-29) [28, 31, 43, 44]. The former B-cell epitope varied at 7 out of 11 positions: 4(S/W), 7 (G/S), 8 (G/N/D/C), $9(\mathrm{Q} / \mathrm{H}), 12(\mathrm{E} /$ G), $13(\mathrm{~S} / \mathrm{V})$ and $14(\mathrm{~S} / \mathrm{G} / \mathrm{V})$, while the latter varied at 3 out of 6 positions: 21 (Q/E/G/D/S/P), $22(\mathrm{~A} / \mathrm{T})$ and 23 (S/G). The T-cell epitope had variations at 11 out of 15 positions: 16 (S/L/P), $17(\mathrm{~S} / \mathrm{P}), 18(\mathrm{Q} / \mathrm{Y}), 19$ (S/Q/T), 20 (D/G/S), 21 (Q/E/G/D/S/P), $22(\mathrm{~A} / \mathrm{T})$ and $23(\mathrm{~S} / \mathrm{G}), 27$ (Q/K/R/H), 28 (L/F/S), 29 (G/R/E). 


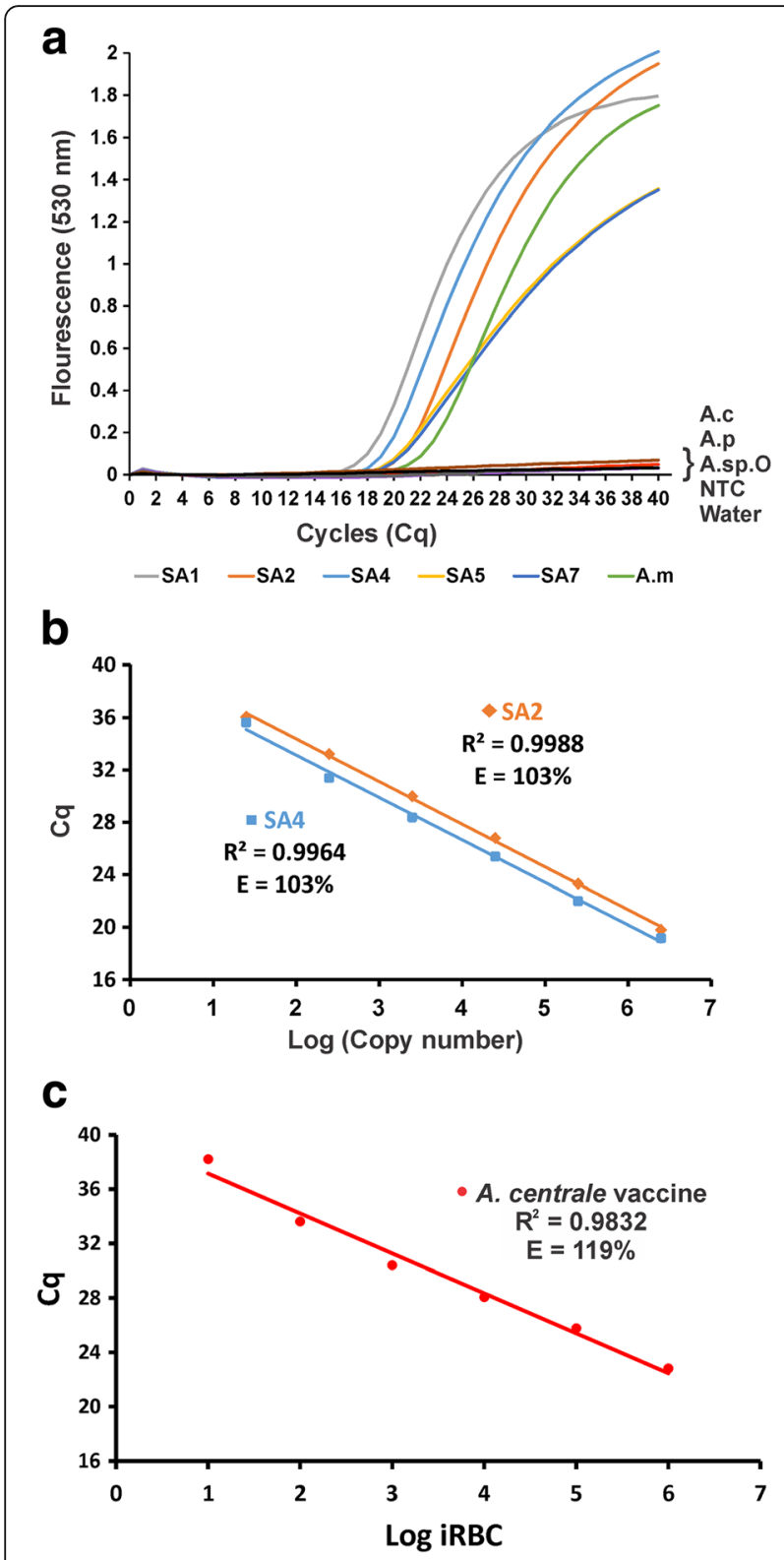

Fig. $2 \mathrm{qPCR}$ amplification of $A$. marginale $m s p 1 \beta$ variants. a $\mathrm{qPCR}$ amplification of plasmid DNA $\left(2.5 \times 10^{7}\right.$ copies) of $A$. marginale msp $1 \beta$ variants (SA1, SA2, SA4, SA5, SA7). Genomic DNA (gDNA) from sample C14 was used as a positive control for A. marginale (A.m) and water as a negative control. gDNA from the A. centrale (A.C) vaccine strain, $A$. phagocytophilum (A.p), Anaplasma sp. (Omatjenne) (A.spO) and a no temple control (NTC) were included in the analysis. $\mathbf{b}$ Detection of tenfold serial dilutions $\left(2.5 \times 10^{7}-2.5 \times 10^{2}\right.$ copies $)$ of plasmid DNA of A. marginale variants SA2 and SA4. c Detection of tenfold serial dilutions of $A$. centrale vaccine strain $\left(10^{6}-10^{1}\right.$ iRBCs) genomic DNA. Abbreviations: $C_{q}$, quantification cycle; $R^{2}$, regression coefficient; $E_{\text {, }}$ assay efficiency

\section{Analysis of Msp1a repeats and msp1a genotypes using RepeatAnalyzer}

For all South African Mspla data collected to date, from this and previous reports $[23,24]$, the frequency

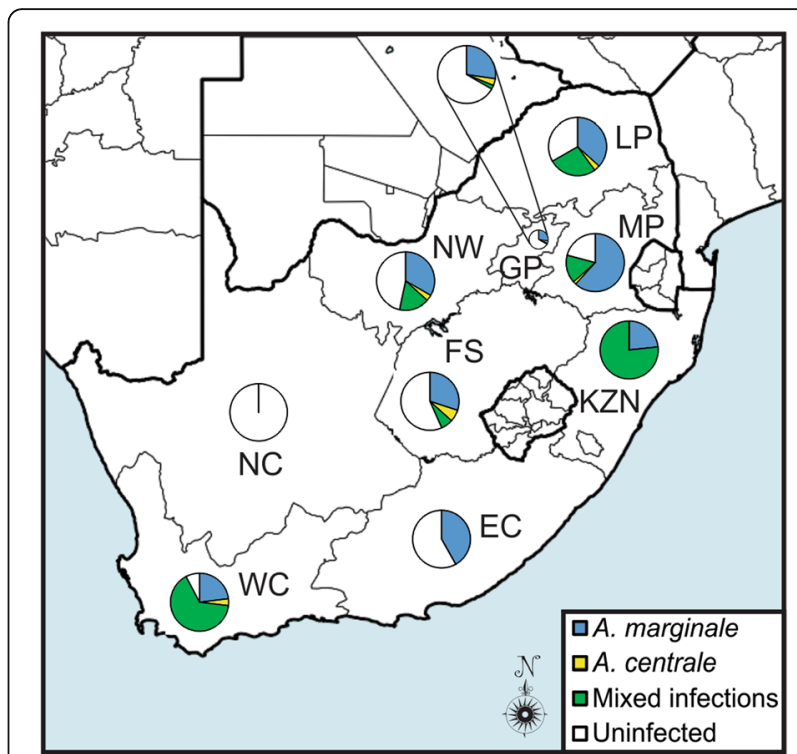

Fig. 3 Map of South Africa showing the occurrence of A. marginale and $A$. centrale in cattle. DNA extracted from blood samples from cattle from all nine provinces of South Africa were tested for $A$. marginale and $A$. centrale using the duplex qPCR assay [20,21]. The pie charts indicate the proportion of samples in each province that were positive, negative or which contained mixed infections. Abbreviations: GP, Gauteng; EC, Eastern Cape; FS, Free State; KZN, KwaZulu-Natal; LP, Limpopo; MP, Mpumalanga; NC, Northern Cape; NW, North West; WC, Western Cape

distribution of Mspla repeats resembled a power-law distribution (Fig. 5a). Unique repeats (those observed only once in all $A$. marginale genotypes in South Africa) were observed in 48 instances; examples of such repeats are G, 39, 44, T, UP29, 83, 145, and 154. Six Msp1a repeats, 13, $37,34,27,4$ and 3 , were found to be most common in South Africa, occurring between 37 and 78 times. There was a normal distribution of $m s p 1 \alpha$ genotype lengths (Fig. 5b) $(\mu=4.26$; $\sigma=1.48)$, which ranged from one to nine repeats. Msp $1 \alpha$ genotypes in South Africa most frequently contained four or five repeats; these occurred 53 (27.9\%) and $49(25.8 \%)$ times, respectively (Fig. 5b). The frequency of genotypes per sample (Fig. 5c) was found to be positively skewed. A total of $78.8 \%$ of the samples contained one (28.2\%), two (23.5\%) or three (27.1\%) genotypes per sample. Four to nine genotypes per sample were also observed, but much less frequently.

To date, a total of $99 \mathrm{Mspla}$ repeats (Fig. 6a) have been described in South African A. marginale genotypes, 71 (71.7\%) of which are unique to the country (Table 2). These repeats are found in a total of $190 \mathrm{msp} 1 \alpha$ genotypes (Fig. 6b), the majority of which appear to be unique to South Africa (Table 3). In general, repeats were fairly evenly distributed around the country (Fig. 6a). The most abundant strains found in this study have been reported previously $[24,25]$. These were SW112. 42432531 


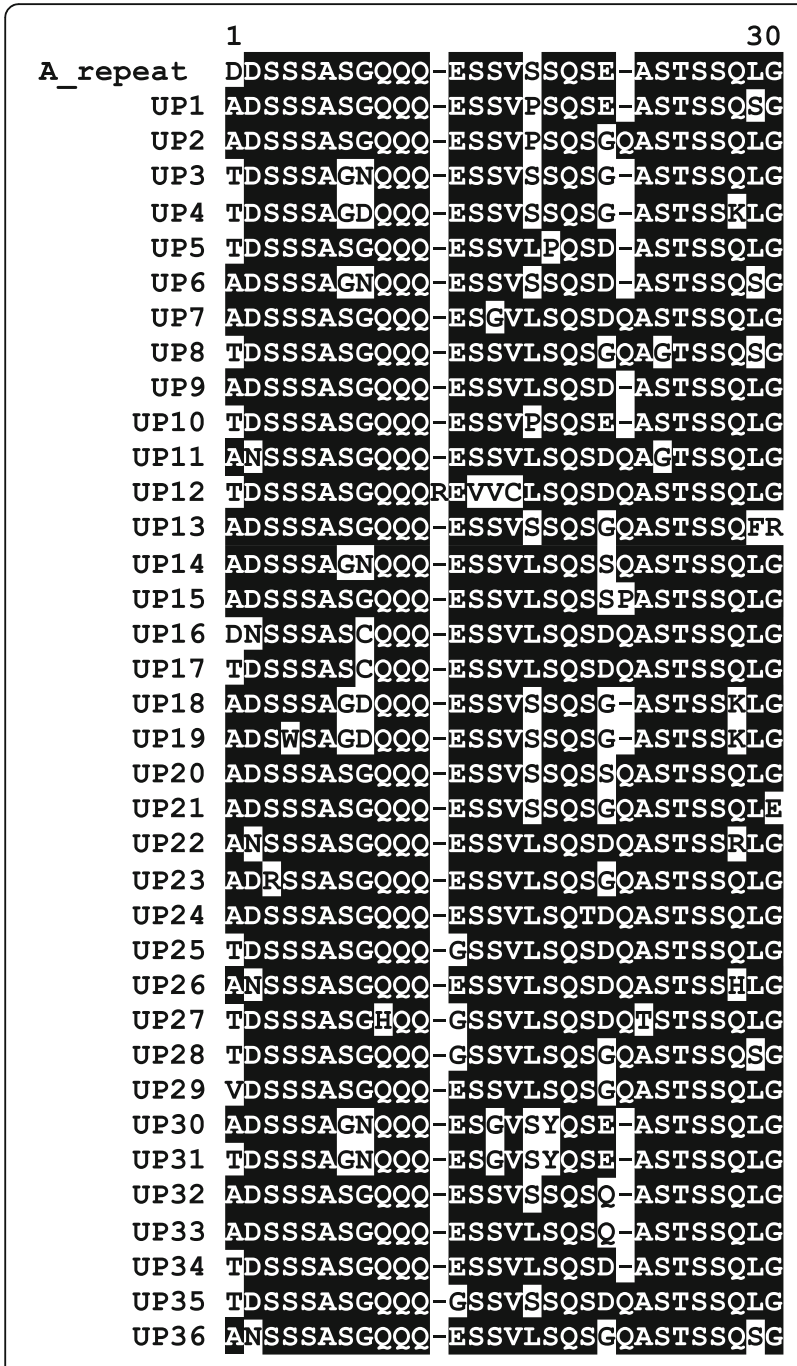

Fig. 4 Novel Mspla sequences repeats found in this study. Thirty-six unique repeats were identified in this study (UP1-UP36) and aligned against the A repeat [28], using the AlignX module of Vector NTI. Identical amino acid residues in the alignment are shown by white text on a black background; variable residues are indicated by black text on a white background

(occurring 12 times in five provinces, Mpumalanga, Eastern Cape, Limpopo, KwaZulu-Natal and North West), SW32. 34 131337 (occurring 6 times in five provinces, Western Cape, Mpumalanga, Gauteng, Limpopo, KwaZuluNatal) and NW-C1-160312. 341333638 (occurring 8 times in five provinces, Mpumalanga, Limpopo, KwaZuluNatal, Free State). Some msp1 $\alpha$ genotypes were found in more than one province, while low abundance genotypes which appeared only once in one province were also detected (Fig. 6b).

Msp1a repeats and $m s p 1 \alpha$ genotypes occurring in five selected countries, Brazil, Argentina, Mexico, South Africa and USA, were compared. The percentage of repeats specific to each country (unique repeats) (Table 2)

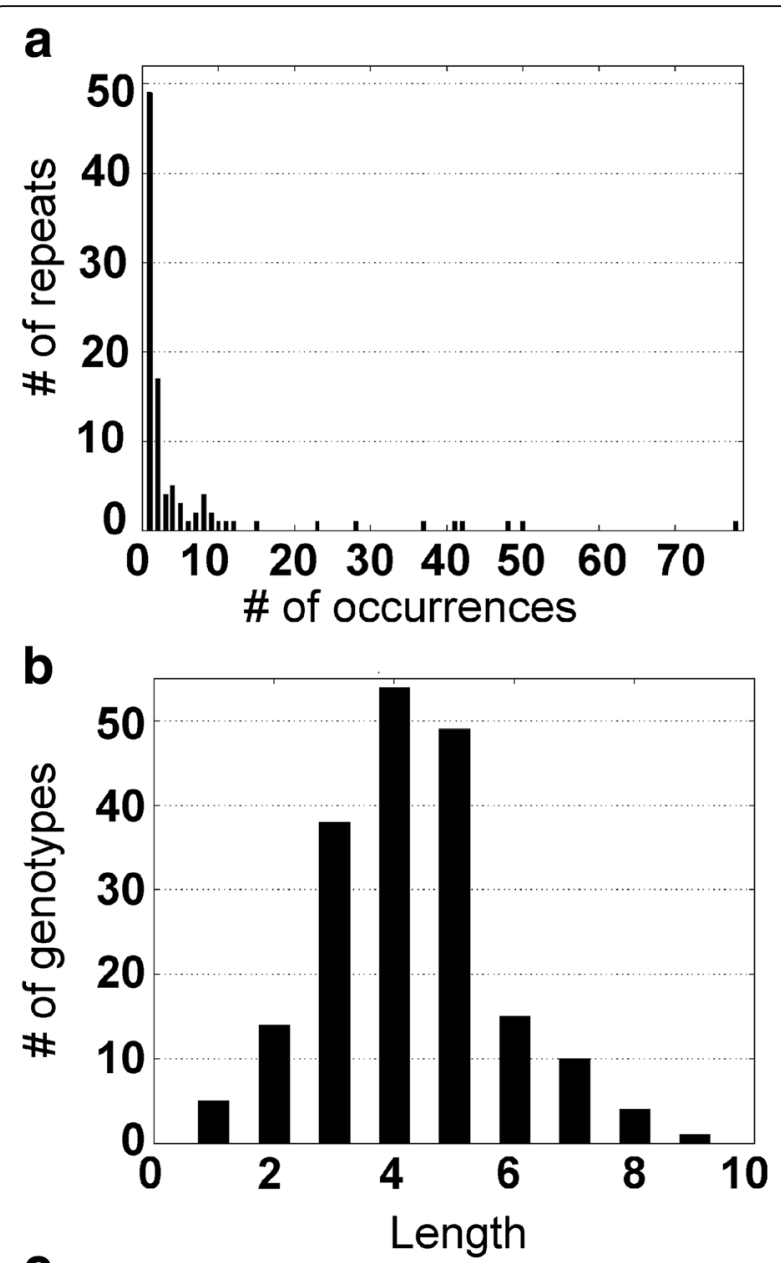

C

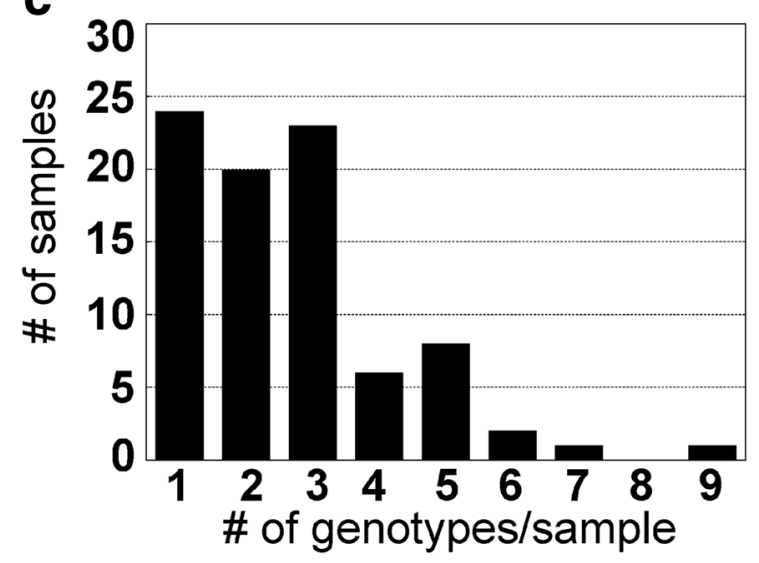

Fig. 5 Mspla repeat and mspla genotype metrics. a Frequency distribution of repeats in Mspla sequences in South Africa generated by RepeatAnalyzer [42]. b Genotype-length distribution of Msp1a repeats in South Africa generated by RepeatAnalyzer. c The frequency of $A$. marginale mspla genotypes found per animal in this study $(n=85)$

was consistently lower than the percentage of unique genotypes (Table 3). The highest percentage of unique repeats $(71.7 \%)$ was found in South Africa, while the 

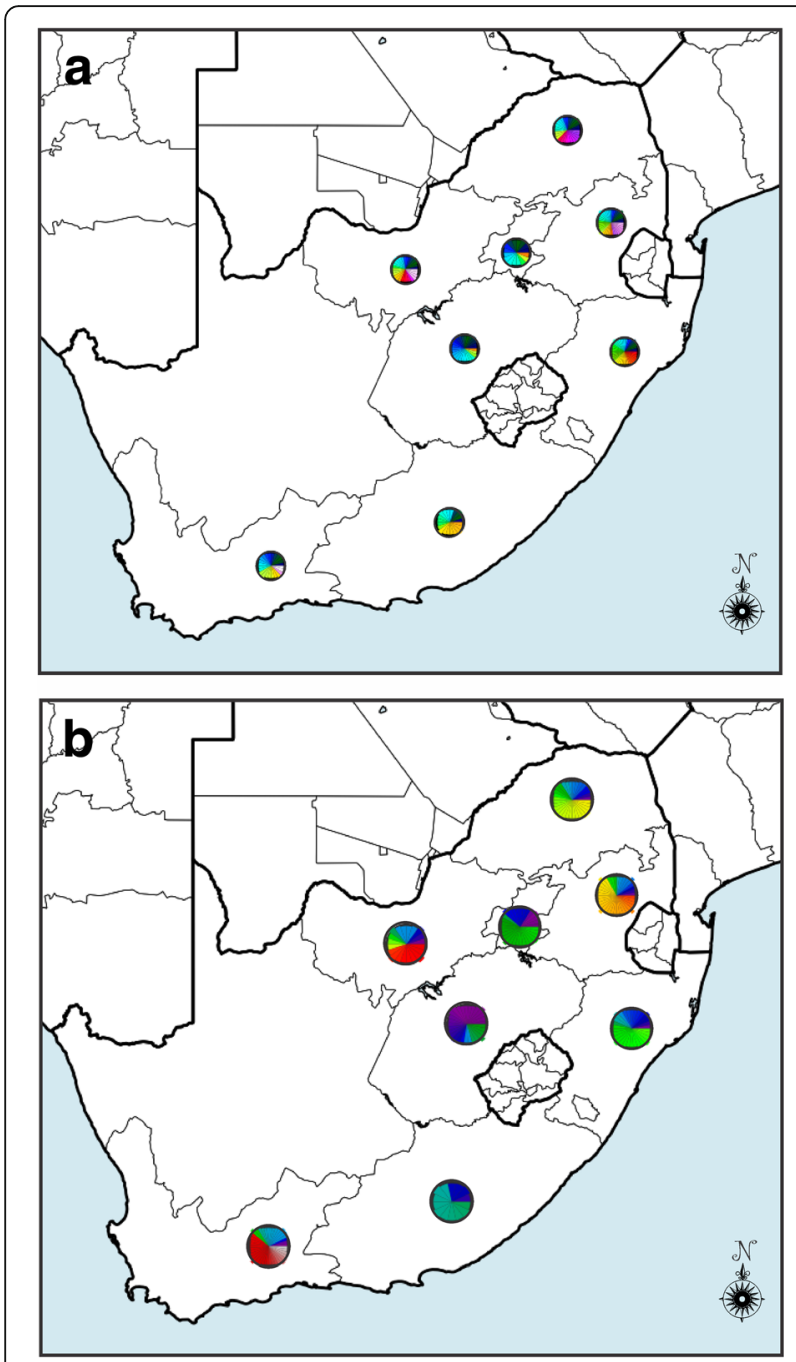

Fig. 6 Geographical distribution of Mspla repeats and strains from A. marginale in South Africa. a Distribution of $99 \mathrm{Mspla}$ repeats from $A$. marginale identified in South Africa in this and previous studies. Different colours in each circle represent different repeats, with more colours indicating a higher repeat diversity in each region. $\mathbf{b}$

Distribution of 190 A. marginale strains identified in South Africa in this and previous studies. Different colours in each circle represent different strains, with more colours indicating a higher strain diversity in each region. Results were generated in RepeatAnalyzer [42]

lowest (18.2\%) was in Brazil (Table 2). The most common repeats, which appeared in all of the countries examined, were $\mathrm{F}$ and $\mathrm{M}$. Eight other common repeats were found to be present in four of the five countries (Table 2). Although many of the Msp1a repeats identified were found in all five countries examined (an average of $42.8 \%$ of Msp1a repeats were unique to each country), very few genotypes were present in more than one country (an average of $91.0 \%$ of the $m s p 1 \alpha$ genotypes were unique to each country). The highest proportions of unique genotypes were found in USA (100\%) and South Africa (99.0\%), with Brazil (78.3\%) having the lowest observed value (Table 3 ). More msp1 $\alpha$ genotypes have been identified in South Africa (190 mspl $\alpha$ genotypes) than in any other country, although this likely due to sampling density. Only two genotypes that have previously been identified in other countries were identified in samples from South Africa: (i) c 5713 18, found in strain Minas-11 (Minas Gerais, Brazil) [24, 45] was identified in two samples from KwaZulu-Natal; and (ii) 1327 27, found in strain UFMG-2 (Minas Gerais, Brazil) $[24,45]$ (also found in the Philippines [39]) was identified in samples from Eastern Cape and Mpumalanga. The genotypes common between South Africa, Brazil and the Philippines represent only $1 \%$ of the total number of genotypes described thus far in South Africa.

\section{Discussion}

We have recently shown [18] that the duplex qPCR assay [20] is a more sensitive method of detecting $A$. marginale and $A$. centrale infections in cattle in South Africa than RLB [22] or nPCR [19] assays. We also detected sequence variation in the msp $1 \beta$ gene in the target region of one of the nPCR internal primers in South African $A$. marginale strains [18]. The msp1 $\beta$ multigene family encodes the Msp1b protein, which has been shown to vary between strains of $A$. marginale [7, 39]. Variation of $0.9-1.4 \%$ between Msp1b peptide sequences has been shown, but Msp1b is stable during the bovine and tick stages of the $A$. marginale life-cycle within a given strain [34]. This variation could be detrimental when it is used as a target for detection of the parasite by diagnostic tests such as the $A$. marginale-specific qPCR [21]. Sequence analysis of the $m s p 1 \beta$ gene in the target region of the qPCR assay in the current study indicated that the msp1 $\beta$ gene of $A$. marginale from cattle in South Africa was highly variable, many samples had multiple msp1 $\beta$ variants (when considering the fulllength of the amplicon sequence), and SNPs were present at six nucleotide positions in the primer- and probe-target areas of the qPCR assay. Eleven msp $1 \beta$ variants were identified in the qPCR target area.

It has been demonstrated that mismatches located towards the 3' end of a PCR primer are potentially detrimental to PCR amplification as they can significantly affect annealing of the primer to the template, leading to underestimation of the initial copy number, or even a complete failure of amplification [46]. However, the SNPs identified in this study did not appear to decrease the efficiency of the qPCR assay. The efficiency of the qPCR assay in detection of variants SA2 and SA4 (with the most SNPs) compared well with that of the qPCR assay in detection of SA1 [18] in which there is no variation in the GPCR target region. Nevertheless, the sensitivity of the qPCR assay could still be compromised if there is more variation in the field than we have 
Table 2 Msp1a repeat analysis for different geographical locations, using RepeatAnalyzer

\begin{tabular}{|c|c|c|c|c|c|}
\hline & \multicolumn{5}{|l|}{ Location } \\
\hline & Brazil & USA & Argentina & Mexico & South Africa \\
\hline Number of unique Mspla repeats & 6 & 10 & 12 & 27 & 71 \\
\hline Total number of Msp1a repeats & 33 & 22 & 33 & 64 & 99 \\
\hline$\%$ unique repeats & 18.2 & 45.5 & 36.4 & 42.2 & 71.7 \\
\hline Other locations with repeats in common & $\begin{array}{l}\text { Arg, Mex, SA, } \\
\text { USA }\end{array}$ & $\begin{array}{l}\text { Arg, Brz, Mex, } \\
\text { SA }\end{array}$ & $\begin{array}{l}\text { Brz, Mex, SA, } \\
\text { USA }\end{array}$ & $\begin{array}{l}\text { Arg, Brz, SA, } \\
\text { USA }\end{array}$ & $\begin{array}{l}\text { Arg, Brz, Mex, } \\
\text { USA }\end{array}$ \\
\hline \multirow{10}{*}{$\begin{array}{l}\text { Common repeats appearing in four or more } \\
\text { countries }\end{array}$} & $\mathrm{F}$ & $\mathrm{F}$ & $\mathrm{F}$ & $\mathrm{F}$ & $\mathrm{F}$ \\
\hline & M & M & M & M & M \\
\hline & 13 & - & 13 & 13 & 13 \\
\hline & 15 & - & 15 & 15 & 15 \\
\hline & 18 & - & 18 & 18 & 18 \\
\hline & 27 & - & 27 & 27 & 27 \\
\hline & B & $B$ & B & B & - \\
\hline & C & $C$ & C & $C$ & - \\
\hline & $Q$ & - & $Q$ & $Q$ & Q \\
\hline & $\tau$ & - & $\mathrm{T}$ & $\tau$ & $\tau$ \\
\hline
\end{tabular}

Abbreviations: Arg Argentina, Brz Brazil, Mex Mexico, SA South Africa, USA United States of America

detected in this study. Moreover, A. marginale has been identified from wildlife in South Africa [47], but the sequence variation in the $m s p 1 \beta$ gene in the parasite in these hosts is unknown.

It should be noted that there are two copies of the msp $1 \beta$ gene in $A$. marginale $[48,49]$, and the primers and probe used in the duplex qPCR assay can amplify the target region in both copies. This would explain a large number of samples containing multiple msp $1 \beta$ gene variants since many samples contained multiple $A$. marginale strains (as shown by msp1 $\alpha$ genotyping), and each strain could contain two different $m s p 1 \beta$ copies. The presence of multiple different copies within a sample could increase the likelihood of detecting $A$. marginale since it increases the chance of a single sample containing a variant that can be detected by the qPCR.

The groEL gene of prokaryotes, homologous to the heat-shock protein gene in eukaryotes [50], is highly conserved but contains variable regions that can be useful in differentiating closely related organisms [51, 52]. In contrast to the $A$. marginale msp $1 \beta$ gene, the groEL genes of $A$. centrale and A. marginale were highly conserved in the target region of the GPCR assay, although SNPs in other regions of this gene were identified. Since the sequence differences targeted by the qPCR primers and probes were highly conserved in all A. centrale and

Table 3 Mspla genotype analysis for different geographical locations, using RepeatAnalyzer

\begin{tabular}{|c|c|c|c|c|c|}
\hline & \multicolumn{5}{|l|}{ Location } \\
\hline & Brazil & USA & Argentina & Mexico & South Africa \\
\hline Number of unique mspla genotypes & 18 & 43 & 15 & 84 & 188 \\
\hline Total number of mspla genotypes & 23 & 43 & 18 & 89 & 190 \\
\hline$\%$ unique genotypes & 78.3 & 100.0 & 83.3 & 94.4 & 99.0 \\
\hline Other locations with genotypes in common & Mex, Arg, SA & - & Brz, Mex & Brz, Arg & $\mathrm{Brz}$ \\
\hline \multirow[t]{7}{*}{ Genotypes occurring in more than one country } & $a \beta \beta \beta \beta \gamma$ & - & $a \beta \beta \beta \beta \gamma$ & $a \beta \beta \beta \beta \gamma$ & - \\
\hline & - & - & $a \beta \beta \beta \gamma$ & $a \beta \beta \beta \gamma$ & - \\
\hline & $a \beta \beta \gamma$ & - & - & $a \beta \beta \gamma$ & - \\
\hline & т 571318 & - & - & - & t 571318 \\
\hline & T 1015 & - & T 1015 & T 1015 & - \\
\hline & $132727^{a}$ & - & - & - & $132727^{\mathrm{a}}$ \\
\hline & - & - & - & $1313^{\mathrm{a}}$ & - \\
\hline
\end{tabular}


A. marginale groEL sequences examined, the groEL gene is, therefore, a good marker for the detection of $A$. centrale infections in cattle in South Africa. However, in a recent study on the occurrence of tick-borne infections in cattle samples from Uganda [53], RLB assay detected more $A$. centrale infections than the qPCR assay, indicating the possibility of groEL gene variants which cannot be detected by the qPCR assay. This highlights the necessity for testing the assay in each region in which it is to be deployed. Further, the detection limits are shown to be approximately ten $\mathrm{iRBC/reaction;} \mathrm{although} \mathrm{this} \mathrm{is}$ not being used as a quantitative assay, this can be used as a guideline for field sample detection.

Only two natural isolates of $A$. centrale have been made in South Africa, the original isolate made by Theiler [54] that is used in the blood vaccine, and a second isolate that was made when unfed adult Rhipicephalus simus ticks collected in the Louis Trichardt district of the Northern Transvaal (now Limpopo) were fed on a splenectomized ox and an $A$. centrale infection was transmitted [17, 55]. Very little work has been done on this strain of $A$. centrale although it has been shown to have a close identity to Theiler's $A$. centrale vaccine strain by phylogenetic analysis of the $16 \mathrm{~S}$ rRNA and groEL genes [56]. The groEL sequence from this strain (accession no. AF414866) [56] was included in our analysis, and, as with all the other $A$. centrale groEL sequences analysed, there was no variation in the qPCR target region. It is possible that some of the $A$. centrale infections detected in field samples in this study were due to this strain.

Our results indicated that $A$. marginale is widespread in cattle in eight of the nine provinces of South Africa. As expected, high percentages (> 70\%) of $A$. marginalepositive samples were identified in KwaZulu-Natal, Western Cape and Mpumalanga, since endemic stability is established in these regions. No A. marginale infections were detected in cattle from the Northern Cape; this is consistent with the results from a recent study [25] and was expected since the tick vectors do not occur in this province. Interestingly, $A$. centrale was also detected in the cattle, although none of them was known to have been vaccinated, and mixed infections of $A$. marginale and $A$. centrale were common. A high percentage of cattle from KwaZulu-Natal and Western Cape were positive for $A$. centrale, suggesting that this organism is more common in the southern provinces of South Africa. However, it was not detected in cattle samples from the Eastern Cape, but this may have been an artefact of the sampling (43 samples were collected from five farms in two of 39 local municipalities, representing only $3.8 \%$ of the area of the Eastern Cape); more samples should, therefore, be sourced from this province to increase confidence in this result. This is the first comprehensive study on the occurrence of $A$. centrale in cattle in all nine provinces of South Africa using a nucleic acidbased method, although we recently reported on the occurrence of this species in cattle in Bergville, KwaZuluNatal province, South Africa [47]. Mixed infections of $A$. centrale and $A$. marginale have been reported in cattle and wildlife in South Africa [47] and in cattle elsewhere $[20,53,57]$. Although multiplex qPCR assays are recommended for detecting tick-borne pathogens, competitive PCR suppression may occur if infection levels are similar between two or more target species, or are higher in one species/target [58]. This can affect assay sensitivity as has been reported with multiple infections of T. parva, Theileria sp. (buffalo) and Theileria sp. (bougasvlei) in buffalo [58]. Decaro et al. [20] partly addressed this problem by increasing the concentration of the A. centrale primers to increase the chance of detecting this pathogen in mixed infections.

Msp1 $\alpha$ genotyping revealed that most qPCR-positive cattle $(71.8 \%$ of samples) in this study were found to be infected with multiple $A$. marginale strains. This is expected in endemic areas and has been reported in previous studies in the USA and the Philippines [36, 39]. Although up to nine $m s p 1 \alpha$ genotypes were found per animal, the most abundant genotypes were one to three genotypes per sample. Competition for limited niches or resources in a single host is likely to increase with increasing number of genotypes and may explain the lower numbers of genotypes per animal. Moreover, in South Africa, oxytetracycline and imidocarb are bought overthe-counter by farmers without the need for a veterinary prescription, and these drugs are commonly used to treat babesiosis, heartwater and anaplasmosis, the most common tick-borne diseases in South Africa [3]. Therefore, treatment regimens used by farmers and veterinarians, which have been shown to reduce infection in animals [2, 59], combined with host immunity [2], may play an important role in maintaining lower numbers of genotypes per animal.

Msp1 $\alpha$ genotype has been shown to be a surrogate indicator for strain antigenicity, with strains with different msp1 $\alpha$ genotypes having different $m s p 2$ repertoires [23]. Futse et al. [60] demonstrated that a single unique $m s p 2$ allele was sufficient for a strain to establish superinfection in the face of robust immunity to a primary infecting strain. Our results may suggest superinfection by genomically distinct $A$. marginale strains, which is thought to be uncommon in the temperate regions of the world but occurs more frequently in the tropics [37, 38, 40]. However, superinfection cannot be proven to have occurred in our samples as the infection progress was not monitored in the animals over time, only assessed at one static time point.

Our results demonstrate the importance of cloning all msp1 $\alpha$ PCR products when genotyping $A$. marginale to 
detect multiple infections per animal. Previous studies have focused on samples with only a single detectable band, and have only sequenced one product. To fully explore the diversity of genotypes in a given sample, an investigator must analyse all msp1 $\alpha$ amplicons obtained. The detection of 36 low abundance, previously undescribed $A$. marginale repeats in this study, emphasizes this point. It should be noted, however, that since $m s p 1 \alpha$ is a repetitive sequence, errors in PCR are possible if amplification halts and one repeat primes amplification on another, leading to genotypes with extra repeats. Such a situation may have occurred in up to six samples (7.1\%) in this study. Errors may also occur due to Taq polymerase slippage early in the PCR, resulting in overor under-representation of certain repeats. Other error sources may be due to low DNA concentration or poor sample quality, which may arise from improper storage or repeated cycles of freezing and thawing of blood samples (reviewed in [61]).

Worldwide, over 250 highly variable Msp1a repeats have been detected to date $[8,31,42]$. The amino acid sequences of the $\mathrm{B}$ - and $\mathrm{T}$-cell epitopes that have previously been identified and shown to be necessary to elicit a protective immune response by Msp1a [28, 31, 32, 43, 44], were found to be variable in the novel Mspla repeats described in this study, and this variation almost certainly has an effect on the overall epitope structure. Such variations should, therefore, be considered when testing Mspla as a protective antigen. Serine residues at positions 4 and 25 , however, were found to be highly conserved; these residues are thought to be important for O-glycosylation and the adhesion function of the protein, which is essential for transmission of $A$. marginale [43].

We found that 28 out of the 99 (22.3\%) Mspla repeats identified in South Africa are also found in strains in other countries, but this does not translate to many shared genotypes, with only two genotypes out of 190 (approximately 1\%) found in common between South Africa and Brazil, and the Philippines. This result is in concordance with a recent study analysing global repeat and strain distribution [31]. These data may suggest that new repeats arise independently in different geographical regions, resulting in the emergence of novel genotypes, which arise from new repeat combinations. Interestingly, one of the two genotypes that was found to be common between South Africa and Brazil (т 5713 18), had a repeat structure which differed by one repeat from one of the world's most common genotypes, т 2213 18, which has been detected seven times in Argentina and Mexico [31] (repeats 57 and 22 differ by eight amino acids). Although the low prevalence of genotypes common between South Africa and the rest of the world may be due to restricted cattle movements, it could also be due to a lack of $A$. marginale genotyping efforts in other parts of Africa and some regions of the world.
We have identified a large number of diverse Mspla repeats which are fairly evenly dispersed in South Africa. A large proportion of these Mspla repeats and msp1 $\alpha$ genotypes are found only in South Africa. High repeat and genotypic diversity, and an even dispersion of repeats are expected in situations where the number of region-specific repeats and genotypes is high [42, 47], which is evident in the South African data. These data may suggest that repeats (and their associated genotypes) are circulating within the country as a whole, a process which may be driven by cattle movement between the high prevalence endemic areas and the presence of tick vectors of $A$. marginale to propagate the pathogen. In fact, more than one genotype was found to be common between three to five provinces, which provides evidence of ongoing movement of cattle between provinces within South Africa. Both artificial and natural selection factors such as the presence and control of competent tick vectors, host immunity and chemotherapy treatment, are strong determinants of $A$. marginale repeat and genotype composition in different areas. This study demonstrates a high genetic variability of the $A$. marginale population in South Africa, which is an important factor to consider in formulating future vaccine design strategies.

\section{Conclusions}

Both A. marginale and A. centrale are prevalent in South Africa. Anaplasma centrale was detected in cattle despite the lack of vaccination with this organism, suggesting that there is a natural transmission cycle of $A$. centrale in South Africa. A total of 190 different msp $1 \alpha$ genotypes of A. marginale have been detected in South Africa, indicating a diversity of genotypes that must be taken into account when developing a vaccine.

\section{Abbreviations \\ $C_{\mathrm{g}}$ : Quantification cycle; DNA: Deoxyribonucleic acid; E: Assay efficiency; EDTA: Ethylenediaminetetraacetic acid; gDNA: Genomic DNA; iRBCs: Infected red blood cells; Msp1a: Major surface protein 1a; msp1a: Gene encoding major surface protein 1a; msp 1 $\beta$ : Gene encoding major surface protein $1 \mathrm{~b}$; NGS: Next-generation sequencing; nPCR: Nested polymerase chain reaction; PCR: Polymerase chain reaction; QPCR: Quantitative real-time polymerase chain reaction; $R^{2}$ : Regression coefficient; RLB: Reverse line blot; rRNA: Ribosomal ribonucleic acid; SNP: Single nucleotide polymorphism}

\section{Acknowledgements}

We would like to acknowledge the following people for their assistance with collection and supply of other blood samples used in this work. Mr. Chimvwele Choopa, samples from the Mnisi Community area; Dr. Anthony Davies, Lydenburg samples; Dr. Dirk Verwoerd, Karan Beef samples; Ms. Corlia

Swanepoel, samples from the UP Experimental Farm; and Dr. Helena Steyn, Agricultural Research Council - Onderstepoort Veterinary Institute, sample 9410.

\section{Funding}

This research is supported by the National Research Foundation (NRF) (Nicola Collins, grant number 81840); Technology Innovation Agency, Tshwane Animal Health Cluster (TIA, TAHC) (Marinda Oosthuizen, grant number TAHC12-00037). The funders had no role in study design, data collection and interpretation, or the decision to submit the work for publication. Any opinion, finding and conclusion or recommendation expressed in this material is that of the author(s) and the NRF does not accept any liability in this regard. 


\section{Availability of data and materials}

The datasets used and analysed during the current study are available from the corresponding author upon reasonable request.

\section{Authors' contributions}

$\mathrm{PH}$ and MEC played equal roles in carrying out all of the experimental work, data analysis and manuscript preparation. HG was involved in the generation and analysis of the amplicon sequencing data. HNC developed RepeatAnalyzer and assisted with Msp1a data analysis. MSM and AM collected and supplied most of the samples used in this study. MCO, KAB and NEC were the study leaders. All authors read and approved the final manuscript.

\section{Ethics approval and consent to participate}

Permission to perform the research was granted regarding Section 20 Animal Diseases Act, 1984 (Act number 34 of 1984), by the Department of Agriculture Fisheries and Forestry, Reference number 12/11/1/1/6. Ethics approval was also granted by the University of Pretoria's Animal Ethics Committee, project number V067/13.

\section{Consent for publication}

Not applicable.

\section{Competing interests}

The authors declare that they have no competing interests.

\section{Publisher's Note}

Springer Nature remains neutral with regard to jurisdictional claims in published maps and institutional affiliations.

\section{Author details \\ ${ }^{1}$ Vectors and Vector-borne Diseases Research Programme, Department of Veterinary Tropical Diseases, Faculty of Veterinary Science, University of Pretoria, Pretoria, South Africa. ${ }^{2}$ Biotechnology Platform, Agricultural Research Council, Onderstepoort, Pretoria, South Africa. ${ }^{3}$ Research and Scientific Services Department, National Zoological Gardens of South Africa, Pretoria, South Africa. ${ }^{4}$ Department of Veterinary Microbiology and Pathology, Washington State University, Pullman, WA, USA. ${ }^{5}$ Inqaba Biotechnical Industries, Hatfield, Pretoria, South Africa. ${ }^{6}$ School of Electrical Engineering and Computer Science, Washington State University, Pullman, WA, USA. ${ }^{7}$ Present Address: National Research Foundation, Brummeria, Pretoria, South Africa. ${ }^{8}$ Present Address: Forestry and Agricultural Biotechnology Institute, University of Pretoria, Pretoria, South Africa.}

\section{Received: 6 June 2017 Accepted: 17 December 2017}

\section{Published online: 03 January 2018}

\section{References}

1. Aubry P, Geale DW. A review of bovine anaplasmosis. Transbound Emerg Dis. 2011;58:1-30.

2. Potgieter FT, Stoltsz WH. Bovine Anaplasmosis. In: Coetzer JAW, Tustin RC, editors. Infectious diseases of livestock. 2nd ed. Cape Town: Oxford University Press; 2004. p. 594-616.

3. de Waal DT. Anaplasmosis control and diagnosis in South Africa. Ann N Y Acad Sci. 2000;916:474-83.

4. Dumler JS, Barbet AF, Bekker CP, Dasch GA, Palmer GH, Ray SC, et al. Reorganization of genera in the families Rickettsiaceae and Anaplasmataceae in the order Rickettsiales: unification of some species of Ehrlichia with Anaplasma, Cowdria with Ehrlichia and Ehrlichia with Neorickettsia, descriptions of six new species combinations and designation of Ehrlichia equi and 'HGE agent' as subjective synonyms of Ehrlichia phagocytophila. Int J Syst Evol Microbiol. 2001;51(6):2145-65.

5. Anaplasmosis. In: The Merck Veterinary Manual. http://www. merckvetmanual.com/circulatory-system/blood-parasites/anaplasmosis. Accessed 20 Dec 2017

6. Theiler A. Anaplasma marginale (Gen. and Spec. Nova): A protozoon of cattle; a cause of the so-called gall-sickness. Transvaal Med J. 1910;5:110-1.

7. Brayton KA, Dark MJ, Palmer GH. Anaplasma. In: Nene V, Kole C, editors. Genome mapping and genomics in animal-associated microbes. Berlin / Heidelberg: Springer-Verlag; 2009. p. 85-116.
8. de la Fuente J, Ruybal P, Mtshali MS, Naranjo V, Shuqing L, Mangold AJ, et al. Analysis of world strains of Anaplasma marginale using major surface protein 1a repeat sequences. Vet Microbiol. 2007;119:382-90.

9. Kocan KM, de la Fuente J, Blouin EF, Garcia-Garcia JC. Anaplasma marginale (Rickettsiales: Anaplasmataceae): recent advances in defining host-pathogen adaptations of a tick-borne rickettsia. Parasitology. 2004;129:S285-300.

10. Kocan KM, De de la Fuente J, Alberto A, Meléndez RD, Fuente D, Guglielmone AA, Mele RD. Antigens and alternatives for control of Anaplasma marginale infection in cattle. Clin Microbiol Rev. 2003;16:698-712.

11. Grau HEG, da Cunha Filho NA, Pappen FG, Farias NA da R. Transplacental transmission of Anaplasma marginale in beef cattle chronically infected in southern Brazil. Rev Bras Parasitol Vet. 2013;22:189-93.

12. Potgieter FT. Tick transmission of anaplasmosis in South Africa. In: Whitehead GB, Gibson JD, editors. Proceedings of the international conference on tick biology and control, 27-29 January 1981. Grahamstown: Tick Research Unit, Rhodes University; 1981. p. 53-6.

13. Potgieter FT, Van Rensburg L. The persistence of colostral Anaplasma antibodies in incidence of in utero transmission of Anaplasma infections in calves under laboratory conditions. Onderstepoort J Vet Res. 1987;54:557-60.

14. Swift BL, Paumer RJ. Vertical transmission of Anaplasma marginale in cattle. Theriogenology. 1976:6:515-21.

15. Theiler A. Anaplasma marginale (gen. and spec. nov.): The marginal points in the blood of cattle suffering from a specific disease. In: Report of the Government Veterinary Bacteriologist, 1908-1909. Pretoria: The Government Printing and Stationery Office; 1910. p. 7-64.

16. Carelli G, Decaro N, Lorusso E, Elia G, Martella V, Buonavoglia C, Ceci L. First report of bovine anaplasmosis caused by Anaplasma centrale in Europe. Ann N Y Acad Sci. 2008;1149:107-10.

17. Potgieter FT. Epizootiology and control of anaplasmosis in South Africa. J S Afr Vet Assoc. 1979:50:367-72.

18. Chaisi ME, Baxter JR, Hove P, Choopa CN, Oosthuizen MC, Brayton KA, et al. Comparison of three nucleic acid-based tests for detecting Anaplasma marginale and Anaplasma centrale in cattle. Onderstepoort J Vet Res. 2017;84:1-9.

19. Molad T, Mazuz ML, Fleiderovitz L, Fish L, Savitsky I, Krigel Y, et al. Molecular and serological detection of $A$. centrale- and A. marginale-infected cattle grazing within an endemic area. Vet Microbiol. 2006:113:55-62.

20. Decaro N, Carelli G, Lorusso E, Lucente MS, Greco G, Lorusso A, et al. Duplex real-time polymerase chain reaction for simultaneous detection and quantification of Anaplasma marginale and Anaplasma centrale. J Vet Diagn Investig. 2008;20:606-11.

21. Carelli G, Decaro N, Lorusso A, Elia G, Lorusso E, Mari V, et al. Detection and quantification of Anaplasma marginale DNA in blood samples of cattle by real-time PCR. Vet Microbiol. 2007;124:107-14.

22. Bekker CPJ, de Vos S, Taoufik A, Sparagano OAE, Jongejan F. Simultaneous detection of Anaplasma and Ehrlichia species in ruminants and detection of Ehrlichia ruminantium in Amblyomma variegatum ticks by reverse line blot hybridization. Vet Microbiol. 2002:89:223-38.

23. Rodríguez J-L, Palmer GH, Knowles DP, Brayton KA. Distinctly different msp2 pseudogene repertoires in Anaplasma marginale strains that are capable of superinfection. Gene. 2005;361:127-32.

24. Mtshali MS, de la Fuente J, Ruybal P, Kocan KM, Vicente J, Mbati PA, et al. Prevalence and genetic diversity of Anaplasma marginale strains in cattle in South Africa. Zoonoses Public Health. 2007:54:23-30.

25. Mutshembele AM, Cabezas-Cruz A, Mtshali MS, Thekisoe OMM, Galindo RC, de la Fuente J. Epidemiology and evolution of the genetic variability of Anaplasma marginale in South Africa. Ticks Tick Borne Dis. 2014;5:624-31.

26. da Silva JB, da Fonseca AH, Barbosa JD. Molecular characterization of Anaplasma marginale in ticks naturally feeding on buffaloes. Infect Genet Evol. 2015:35:38-41.

27. Palmer GH, Barbet AF, Davis WC, McGuire TC. Immunization with an isolate-common surface protein protects cattle against anaplasmosis. Science. 1986;231:1299-302.

28. Allred DR, McGuire TC, Palmer GH, Leib SR, Harkins TM, McElwain TF, Barbet AF. Molecular basis for surface antigen size polymorphisms and conservation of a neutralization-sensitive epitope in Anaplasma marginale. Proc Natl Acad Sci USA. 1990;87:3220-4

29. de la Fuente J, Lew A, Lutz H, Meli ML, Hofmann-Lehmann R, Shkap V, et al. Genetic diversity of Anaplasma species major surface proteins and implications for anaplasmosis serodiagnosis and vaccine development Anim Health Res Rev. 2005;6:75-89. 
30. Estrada-Peña A, Naranjo V, Acevedo-Whitehouse K, Mangold AJ, Kocan KM de la Fuente J. Phylogeographic analysis reveals association of tick-borne pathogen, Anaplasma marginale, MSP1a sequences with ecological traits affecting tick vector performance. BMC Biol. 2009;7:57.

31. Cabezas-Cruz A, Passos LMF, Lis K, Kenneil R, Valdés JJ, Ferrolho J, et al. Functional and immunological relevance of Anaplasma marginale major surface protein 1a sequence and structural analysis. PLoS One. 2013;8:e65243.

32. de la Fuente J, Kocan KM, Blouin EF, Zivkovic Z, Naranjo V, Almazán C, et al. Functional genomics and evolution of tick-Anaplasma interactions and vaccine development. Vet Parasitol. 2010;167:175-86.

33. Palmer GH, Rurangirwa FR, McElwain TF. Strain composition of the ehrlichia Anaplasma marginale within persistently infected cattle, a mammalian reservoir for tick transmission. J Clin Microbiol. 2001;39:631-5.

34. Bowie MV, de la Fuente J, Kocan KM, Blouin EF, Barbet AF. Conservation of major surface protein 1 genes of Anaplasma marginale during cyclic transmission between ticks and cattle. Gene. 2002;282:95-102.

35. de la Fuente J, Garcia-Garcia JC, Blouin EF, Saliki JT, Kocan KM. Infection of tick cells and bovine erythrocytes with one genotype of the intracellular ehrlichia Anaplasma marginale excludes infection with other genotypes. Clin Vaccine Immunol. 2002;9:658-68.

36. Palmer GH, Knowles DP, Rodriguez JL, Gnad DP, Hollis LC, Marston T, Brayton KA. Stochastic transmission of multiple genotypically distinct Anaplasma marginale strains in a herd with high prevalence of Anaplasma infection. J Clin Microbiol. 2004;42:5381-4.

37. Ueti MW, Tan Y, Broschat SL, Castañeda Ortiz EJ, Camacho-Nuez M, Mosqueda JJ, et al. Expansion of variant diversity associated with a high prevalence of pathogen strain superinfection under conditions of natural transmission. Infect Immun. 2012;80:2354-60.

38. Esquerra EV, Herndon DR, Mendoza FA, Mosqueda J, Palmer GH. Anaplasma marginale superinfection attributable to pathogen strains with distinct genomic backgrounds. Infect Immun. 2014;82:5286-92.

39. Ybañez AP, Ybañez RHD, Claveria FG, Cruz-Flores MJ, Xuenan X, Yokoyama $\mathrm{N}$, Inokuma $\mathrm{H}$. High genetic diversity of Anaplasma marginale detected from Philippine cattle. J Vet Med Sci. 2014;76:1009-14.

40. Castañeda-Ortiz EJ, Ueti MW, Camacho-Nuez M, Mosqueda JJ, Mousel MR, Johnson WC, Palmer GH. Association of Anaplasma marginale strain superinfection with infection prevalence within tropical regions. PLoS One 2015;10:e0120748.

41. Lew AE, Bock RE, Minchin CM, Masaka S. A mspla polymerase chain reaction assay for specific detection and differentiation of Anaplasma marginale isolates. Vet Microbiol. 2002;86:325-35.

42. Catanese HN, Brayton KA, Gebremedhin AH. RepeatAnalyzer: a tool for analysing and managing short-sequence repeat data. BMC Genomics. 2016;17:422

43. Garcia-Garcia JC, de la Fuente J, Kocan KM, Blouin EF, Halbur T, Onet VC, Saliki JT. Mapping of B-cell epitopes in the N-terminal repeated peptides of Anaplasma marginale major surface protein 1a and characterization of the humoral immune response of cattle immunized with recombinant and whole organism antigens. Vet Immunol Immunopathol. 2004:98:137-51.

44. Brown WC, McGuire TC, Mwangi W, Kegerreis KA, Macmillan H, Lewin HA, Palmer GH. Major histocompatibility complex class II DR-restricted memory CD4+ T lymphocytes recognize conserved immunodominant epitopes of Anaplasma marginale major surface protein 1a. Infect Immun. 2002;70:5521-32.

45. Pohl AE, Cabezas-Cruz A, Ribeiro MFB, da Silveira JAG, Silaghi C, Pfister K, Passos LMF. Detection of genetic diversity of Anaplasma marginale isolates in Minas Gerais, Brazil. Rev Bras Parasitol Vet. 2013;22:129-35.

46. Stadhouders R, Pas SD, Anber J, Voermans J, Mes THM, Schutten M. The effect of primer-template mismatches on the detection and quantification of nucleic acids using the 5' nuclease assay. J Mol Diagn. 2010;12:109-17.

47. Khumalo ZTH, Catanese HN, Liesching N, Hove P, Collins NE, Chaisi ME, et al. Characterization of Anaplasma marginale subsp. centrale strains by use of msplas genotyping reveals a wildlife reservoir. J Clin Microbiol. 2016:54:2503-12.

48. Barbet AF, Allred DR. The msp1 beta multigene family of Anaplasma marginale: nucleotide sequence analysis of an expressed copy. Infect Immun. 1991:59:971-6.

49. Barbet AF, Palmer GH, Myler PJ, McGuire TC. Characterization of an immunoprotective protein complex of Anaplasma marginale by cloning and expression of the gene coding for polypeptide Am105L. Infect Immun. 1987:55:2428-35.
50. Sumner JW, Nicholson WL, Massung RF. PCR amplification and comparison of nucleotide sequences from the groESL heat shock operon of Ehrlichia species. J Clin Microbiol. 1997;35:2087-92.

51. Yu X, Zhang X, McBride JW, Zhang Y, Walker DH. Phylogenetic relationships of Anaplasma marginale and "Ehrlichia platys" to other Ehrlichia species determined by GroEL amino acid sequences. Int J Syst Evol Microbiol. 2001; 51:1143-6.

52. Rymaszewska A. Divergence within the marker region of the groESL operon in Anaplasma phagocytophilum. Eur J Clin Microbiol Infect Dis. 2008;27: 1025-36.

53. Byaruhanga C, Collins NE, Knobel D, Chaisi ME, Vorster I, Steyn HC, Oosthuizen MC. Molecular investigation of tick-borne haemoparasite infections among transhumant zebu cattle in Karamoja region. Uganda Vet Parasitol Reg Stud Reports. 2016;3-4:27-35.

54. Theiler A. Further investigations into anaplasmosis of South African cattle. In: First Rep Dir Vet Res Union South Africa. Pretoria: The Government Printing and Stationery Office; 1911. p. 7-46.

55. Potgieter FT, van Rensburg L. Tick transmission of Anaplasma centrale. Onderstepoort J Vet Res. 1987;54:5-7.

56. Lew AE, Gale KR, Minchin CM, Shkap V, de Waal DT. Phylogenetic analysis of the erythrocytic Anaplasma species based on 165 rDNA and GroEL (HSP60) sequences of $A$. marginale, $A$. centrale, and $A$. ovis and the specific detection of $A$. centrale vaccine strain. Vet Microbiol. 2003;92:145-60.

57. Belkahia H, Ben Said M, Alberti A, Abdi K, Issaoui Z, Hattab D, et al. First molecular survey and novel genetic variants' identification of Anaplasma marginale, A. centrale and A. bovis in cattle from Tunisia. Infect Genet Evol. 2015:34:361-71.

58. Pienaar R, Potgieter FT, Latif AA, Thekisoe OMM, Mans BJ. Mixed Theileria infections in free-ranging buffalo herds: implications for diagnosing Theileria parva infections in cape buffalo (Syncerus caffer). Parasitology. 2011;138:884-95.

59. Reinbold JB, Coetzee JF, Hollis LC, Nickell JS, Riegel C, Olson KC, Ganta RR. The efficacy of three chlortetracycline regimens in the treatment of persistent Anaplasma marginale infection. Vet Microbiol. 2010;145:69-75.

60. Futse JE, Brayton KA, Dark MJ, Knowles DP, Palmer GH. Superinfection as a driver of genomic diversification in antigenically variant pathogens. Proc Natl Acad Sci USA. 2008;105:2123-7.

61. Pompanon F, Bonin A, Bellemain E, Taberlet P. Genotyping errors: causes, consequences and solutions. Nat Rev Genet. 2005;6:847-59.

\section{Submit your next manuscript to BioMed Central and we will help you at every step:}

- We accept pre-submission inquiries

- Our selector tool helps you to find the most relevant journal

- We provide round the clock customer support

- Convenient online submission

- Thorough peer review

- Inclusion in PubMed and all major indexing services

- Maximum visibility for your research

Submit your manuscript at www.biomedcentral.com/submit 